\title{
No dentistry-specific mishaps remain on Never Events list
}

Wrong site tooth extraction has been removed from NHS England's list of Never Events.

The change will come into effect on 1 April, but has been confirmed in the latest revision to the Never Events list which was published in February. ${ }^{1}$

The NHS defines Never Events as incidents with 'the potential to cause serious patient harm or death' that are 'wholly preventable where guidance or safety recommendations that provide strong systemic protective barriers are available at a national level and have been implemented by healthcare providers'

The amendment to the list was recommended by an interdisciplinary, multi-stakeholder working group convened by NHS Improvement, whose review found that the barriers available and in place to prevent occurrences of wrong site tooth extraction are insufficient to meet the Never Event definition.

The same recommendation has also been made by the Healthcare Safety Investigation Branch in its recentlypublished National Learning Report on investigations into Never Events, ${ }^{2}$ which details ten incident types across healthcare, including wrong site dental extraction, which it says do not meet the definition.

While this development means there are no longer any dentistry-specific mishaps classified as Never Events by the NHS, incidents of wrong site extraction are still classified as Patient Safety Incidents, and should continue to be reported, and managed, accordingly.

Further details of changes to the NHS Never Events list are available at https:// www.england.nhs.uk/patient-safety/ revised-never-events-policy-andframework/.

\section{References}

1. NHS Improvement. Never Events list 2018. January 2018, updated February 2021. Available at: https://www.england.nhs.uk/wp-content/ uploads/2020/11/2018-Never-Events-List-updatedFebruary-2021.pdf (accessed 1 March 2021).

2. Healthcare Safety Investigation Branch. National Learning Report. Never Events: analysis of HSIB's national investigations. Independent report by the Healthcare Safety Investigation Branch I2020/006. January 2021. Available at: https://www.hsib.org uk/documents/272/HSIB_Never_Events___analysis of_HSIBs_national_investigations_Report_V09.pdf (accessed 1 March 2021).

\section{Oral health campaign gains momentum}

An oral health campaign that created colourful, high impact billboard posters in Stoke-on-Trent in 2018 to influence the eating habits of young people in the city is going from strength to strength.

The KeepStokeSmiling campaign's aim was to highlight the importance of teeth and looking after them in an area with some of the highest rates of dental decay in children and young adults in the country [Stoke-on-Trent and North Staffordshire]. It was initiated by the orthodontic team

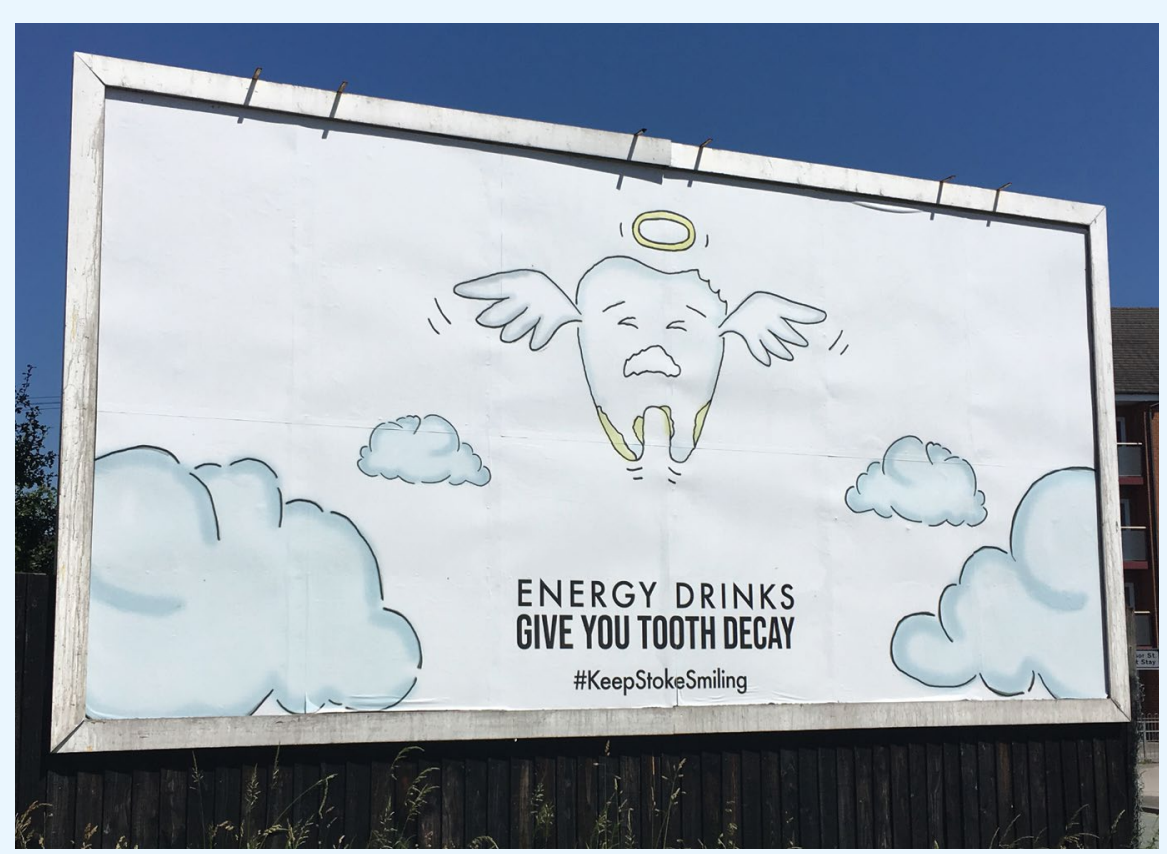

and scientist and politician Professor Lord Winston, among others. This has helped KeepStokeSmiling reach around 1,500 followers across five social media platforms. Each platform has a slightly different target audience. All are highly effective at getting our message across'.

The latest campaign is 'Fizz-Free Schools'. In conjunction with the local council and dental public health team, a 'Fizz-Free tool-kit' has been developed which will be sent to all local schools. Advertising giants JCDecaux have agreed to support this campaign which will see new billboards and oral health messages on JCDecaux-owned street furniture in the city. Once established in Stoke and Staffordshire, it is hoped it will become a national model that can be copied by other NHS Trusts, councils or dental public health teams.

Other hospital orthodontic departments around the country have started to follow Stoke's lead - including Derby, Oxford, Burton, Chesterfield, Sheffield and Dorset and Stafford. By promoting rather than preaching oral health messages to young people, it is hoped these individuals will make the decision to look after their teeth.

Twitter: @KeepGBsmiling. \#keepbritainsmiling \#fizzfreeschools. 